Distinciones en el cine: el dualismo filosófico a la luz del signo peirceano

Ezequiel Iván Duarte

Question, Vol. 1, N. 62, e160, abril-junio 2019

ISSN 1669-6581 | https://doi.org/10.24215/16696581e160

http://perio.unlp.edu.ar/ojs/index.php/question

FPyCS | Universidad Nacional de La Plata

La Plata | Buenos Aires | Argentina

\title{
Distinciones en el cine: el dualismo filosófico a la luz del signo peirceano
}

Distinctions in film: philosophical dualism in light of the Peircean sign

Ezequiel Iván Duarte ezequieldriver8@gmail.com

http://orcid.org/0000-0002-5600-628X

Instituto de Investigaciones en Comunicación; Facultad de Periodismo

y Comunicación Social; Universidad Nacional de La Plata (Argentina)

\section{Resumen}

El presente ensayo aborda el dualismo tradicional entre forma y materia que se da en los campos filosófico y artístico, concentrándose en la división del signo entre significante y significado. Esta bifurcación contribuye al representacionalismo, que postula la separación ontológica entre el mundo-en-sí y las imágenes mentales que de él nos hacemos. De aquí se sigue que sea importante una recuperación del signo peirceano ya que, a diferencia del signo Question, Vol. 1, N.o 62, abril-junio 2019. ISSN 1669-6581 
estructuralista o de la división signo/símbolo de Ernst Cassirer, reintroduce a la imagen en toda su materialidad jamás reducida a un mero psicologismo (y muchísimo menos a la lingüística). El signo alegórico de Walter Benjamin va por el mismo camino. Así, ofrecemos finalmente un ejemplo cinematográfico: tomamos un par de secuencias del largometraje de Jorge Acha Habeas Corpus (1986) para pensar las implicancias de la concepción peirceana del signo aquí desarrollada en relación con el arte de vanguardia y sus vínculos con una ontología procesualrelacional o comunicacional.

Palabras clave: Cine y comunicación; representación; hilemorfismo; Charles Sanders Peirce; Adrian J. Ivakhiv.

\section{Abstract}

This essay tackles the traditional dualism in philosophy and the arts between form and matter, focusing in the division of the sign between signifier and signified. This bifurcation subscribes to representationalism which postulates the ontological divide between the world-in-itself and the mental images we make from it. Hence it is important to recover the Peircean sign because, unlike the structuralist sign or Ernst Cassirer's sign/symbol distinction, it reintroduces the image in all its materiality, never reduced to a simple psychologism (and much less to linguistics). Walter Benjamin's allegorical sign follows the same path. Therefore, in the end, we offer a cinematographic example: we take a couple of sequences from Jorge Acha's feature film Habeas Corpus (1986) and think about the implications of the peircean conception of the sign developed here in relation to avant-garde art and its links to a process-relational or communicational ontology.

Keywords: Cinema and communication; representation; hylemorphism; Charles Sanders Peirce; Adrian J. Ivakhiv.

\section{Hilemorfismo}

Partamos de una escisión clásica en el mundo de la filosofía y de su avatar en el mundo del arte. Se trata de la separación entre idea y materia, de destacada progenie. La ontología grecolatina dominante ha tendido a una anulación del cuerpo en la naturaleza que llega hasta 
la concepción saussureana del signo. Su obsesión con la unidad, lo eterno y necesario la ha separado del universo material, que implica cambio, multiplicidad, contingencia.

En el origen tenemos el desprecio de los filósofos hacia las actividades manuales, hacia las labores artesanales. Es que el trabajo manual se asociaba al mundo 'inferior' de los fenómenos (ilusorios, contingentes) en contraste con el edificio monumental y perfecto de la Idea. Este desprecio no deja de ser hipócrita, puesto que las observaciones de los estudiosos dependen en gran medida de labores experimentales (Dewey, 1929). La ruptura newtoniana con la metafísica cartesiana y la consecuente consolidación del método empírico en las ciencias contribuyó a la división cada vez mayor entre éstas y la filosofía.

Aquí aparece uno de los términos clave: la experiencia, aquello que restaura el lugar del cuerpo, de la mente (ahora sólo parte de lo que experimenta) como parte del cuerpo reinstaurado en la naturaleza, en el mundo físico en permanente relación/transformación respecto del sujeto. Pero no nos adelantemos. Volvamos a la escisión inicial. Posee distintos avatares: idea/materia, mente/cuerpo, hombre/naturaleza, carne/espíritu, forma/contenido. Dualismo filosófico que se traslada a diversos campos, entre ellos el del arte.

Aquí nos interesará en particular una de las derivaciones del hilemorfismo y del dualismo en él implicado, aquella del signo dividido en significante y significado, instaurada por el estructuralismo. Se trata de una concepción representacionalista a la que opondremos, como alternativa, la visión del signo como alegoría en Walter Benjamin y, en relación profunda con ésta, el signo y la representación semiótica concebidas por Charles Sanders Peirce.

De acuerdo con Barad (2007), el representacionalismo es "la idea de que las representaciones y los objetos (sujetos, acontecimientos o estados de cosas) que pretenden representar son independientes las unas de los otros" (p. 28).

El representacionalismo es la creencia en la distinción ontológica entre las representaciones y aquello que pretenden representar; en particular, se sostiene que aquello que es representado es independiente de toda práctica de representación. Esto es, se asume que existen dos tipos de entidades independientes y distintos: representaciones y entidades a ser representadas (2007: 46)

Se trata de un problema que afecta no solo al campo del arte, sino también al de la ciencia y al del lenguaje en general. Barad explica que:

tanto los realistas científicos como los constructivistas sociales creen que el conocimiento científico [y las obras de arte, agregamos nosotros] (en sus múltiples formas representacionales como son los conceptos teóricos, los gráficos, los trazados de partículas 
y las imágenes fotográficas) media nuestro acceso al mundo material; donde difieren es en la cuestión del referente, si el conocimiento científico representa las cosas en el mundo tal y como son (por ejemplo, la naturaleza) u objetos producto de actividades sociales (por ejemplo, la cultura), pero ambos grupos suscriben al representacionalismo (2007: 48).

Consiste, en definitiva, en una concepción mentalística de la representación que, como el signo saussuriano, queda reducida a un psicologismo (Es cierto que, en desarrollos posteriores, se le otorga materialidad al significante en contraste con el significado. Pero esta bifurcación de la naturaleza sostiene aún el representacionalismo). Será la representación en tanto que semiosis, sostenida en un signo trivalente, la que nos permitirá salir del atolladero. Pero primero, veamos la alternativa que propone el signo alegórico benjaminiano.

\section{Alegoría}

Walter Benjamin, en su análisis del Trauerspiel, no reniega ni de los detalles de puesta en escena ni de los puramente narrativos. Asimismo, ofrece una alternativa al pseudo-dualismo signo/símbolo de la tradición de Ernst Cassirer (2015). Para éste el símbolo es un tipo de signo, pero no todo signo será un símbolo. Mientras que el signo sería arbitrario y unívoco, el símbolo implicaría semejanza y relación necesaria. Se trataría de un significado que evoca a otro significado, a diferencia del signo, donde un significante signa un significado.

Benjamin, en cambio, alzará el concepto de alegoría, oponiéndose a la totalidad pretendida por el símbolo. La alegoría enrarece los procesos de comunicación y experimentación del arte, la relación entre imagen y significación deja de ser unívoca, se produce un pliegue o desplazamiento metonímico que anuncia los límites del dualismo significante/significado y de cualquier concepción del signo que se le parezca. Así, "en la alegoría la facies hippocratica [rostro moribundo] de la historia se abre ante los ojos del observador como un paisaje primigenio petrificado" (Benjamin, 2012: 208-209). Se trata de la ruina que constituye la imagen fija de la historia.

En el campo específicamente cinematográfico, Marcos Tabarrozzi, por su parte, indica que

si lo alegórico había sido una herramienta de todo el cine moderno para rebatir las proyecciones simbólicas del cine clásico, las culturas sujetas a procesos de subordinación lo exploraban desde una perspectiva diferente, como modo de imaginación y acción para la transformación social. La asunción de la alegoría como figura principal del cine no 
hegemónico implica un terreno hermenéutico polémico pero sugerente para pensar las manifestaciones fílmicas de la Nación y el Pueblo (2016: 34).

De este modo, el autor explica que, si bien "la representación alegórica registra antecedentes en toda la historia del cine mundial" (2016: 35), en los países subordinados, caracterizados por el trauma de "las dificultades de autorepresentación y las tensiones entre la Nación y el Poder fáctico (económico, neocolonial, militar, etc.)" (Ibídem), se produjeron películas que pudieran intervenir en la elucidación de ese conflicto interno.

Miguel Vedda explica que

la alegoría no es tan solo 'tropo que dice una cosa para aludir a otra diferente, sino que consiste en la divergencia entre ambas y, en tal sentido, da una información sobre el 'mundo' que no coincide con su sentido, así como este no coincide con la representación' (Benjamin, 2012: 41).

"La alegoría", dice el propio Benjamin, "no es una lúdica técnica de imágenes, sino expresión, así como el lenguaje e incluso la escritura son expresión" (2012: 205). Y es el campo expresivo el que se desplaza entre el pensamiento y las cosas (ya no hay reflejo especular ni dualismo).

\section{Semiosis}

Recapitulemos, una vez más: tenemos una división tradicional en el mundo de la filosofía, que en líneas generales podemos caracterizar como división jerárquica entre la idea y la materia, con todos sus derivados, con toda su progenie de dualismos; entre ella, la del signo como bivalente (significante/significado en Saussure y los estructuralistas, división entre signo y símbolo en Cassirer). El signo alegórico de Benjamin nos ofrecía una alternativa. Ahora, sostendremos que la alegoría benjaminiana, al proponer un pliegue o desplazamiento metonímico, un movimiento figural expresivo, se acerca a la concepción semiótica peirceana, que también implica un continuum ideal-material que, en consecuencia, desafía al dualismo filosófico.

Charles Sanders Peirce (2016) distingue tres tipos de signos a partir de la relación que los signos-vehículos (representámenes) tengan con sus objetos: íconos, índices y símbolos. En los primeros prima la semejanza (que Cassirer adjudicaba al símbolo); en los segundos, la conexión física (el humo índice del fuego); en los terceros, la conexión con el objeto es debida a la labor de la mente interpretadora de signos (ley). El signo-vehículo peirceano está en lugar 
de otra cosa, su objeto, pero ese objeto es parte de la relación triádica que conforma al signo, y que incluye a su vez un signo aún más desarrollado, el interpretante (que juega a nivel de las relaciones paradigmáticas). De este modo, ya no tenemos una realidad referente que ilumina una realidad referida, sino un mismo movimiento comunicacional que constituye lo real.

Así, el signo no sólo gana en virtualidad (por medio del interpretante) sino que recupera al cuerpo, a la materialidad por la relación comunicacional que implica con lo real (por intermedio del objeto como aquello que el signo reemplaza pero que es, potencialmente y por medio del destierro del psicologismo, a su vez también signo). El signo se vuelve así algo que reenvía a otra cosa distinta de sí, como en el desplazamiento alegórico de Benjamin. El trabajo sígnico es mental-corporal en continuum, no simplemente mental o mental-corporal en escisión; y trabaja por reenvíos constantes: el interpretante permite una apertura tipo rizoma o como si se tratara de un cristal que va extendiéndose en su solución.

¿Cómo trabajan la alegoría y el signo tricotómico, junto a la representación semiótica, en el cine? Emil Visnovsky (2018) explica la particular idea de representación en Peirce mediante un análisis conjunto de un filósofo pragmático posterior, Richard Rorty. Este se muestra reticente al lógico de Massachusetts justamente por su empleo del concepto de representación, que Rorty rechaza. Visnovsky considera que "Rorty no se percató de que Peirce usaba el término no en sentido mentalístico, pictórico y reflejante sino en sentido semiótico" (p. 17). No hablamos ya de representación mental, de efecto especular, mimético (en sentido craso). En lugar de mirroring ("reflejar" como en un espejo), la representación peirceana trata de standing for (aquí el español no nos ofrece una traducción del todo adecuada ya que "representar" resulta redundante; debe entenderse, quizás, como "estar en lugar de"). La representación (y la semiosis) peirceana es un proceso (o movimiento figural) del mismo modo que el arte audiovisual es "lo Real-como-proceso o realidad procesual" (Mullarkey, 2009: 76).

Esta procesualidad 'disparada' por el interpretante sea quizás más fácilmente observable, más identificable, en el cine de vanguardia o experimental, que tiende tanto a la alegoría como a la asociatividad en apariencia absolutamente libre, pero que siempre puede determinarse a partir de un 'germen' (que puede ser un plano en particular o un elemento dentro de un plano o un trabajo con la textura o la luz). Y si a la experimentación plástica le sumamos las condiciones de producción y la perspectiva latinoamericanas (es decir, subordinadas), ese trabajo del interpretante se asocia al signo alegórico benjaminiano con cierta claridad. 


\section{Un ejemplo práctico}

Aquí podemos retomar la idea de alegoría de Walter Benjamin. Es muy importante en su caracterización del arte barroco. Si entendemos al barroco como ethos histórico antes que como un período del arte europeo centrado en el siglo XVII, el barroco retornaría como modo de vida con su respectiva expresión estética, sobre todo en América Latina, a partir de un retrabajo de los códigos del siglo de oro, que daría origen a lo que ha dado en llamarse como neobarroco o al barroso y neobarroso de Néstor Perlongher, por ejemplo.

La alegoría para Benjamin remite al cadáver, a la muerte. En ella se estampa la historia en lo que tiene de atemporal, doloroso, fallido; la historia es la historia del sufrimiento del mundo. La historia como cuerpo despedazado, como ruina. La alegoría informa sobre el mundo de modo tal que desplaza su sentido el cual, a su vez, no coincide con la representación. Se trata de un pliegue de metáforas (que en su sucesión conforman una metonimia), de una explosión del interpretante: no hay dualismo posible, sino proliferación de sentidos.

Así, las nociones de linealidad y eternidad temporales se ven desafiadas en una semiosis infinita y rizomática. Pero quizás sea mejor ver todo esto con un ejemplo desde la vanguardia. Suele entenderse que el cine experimental argentino, es decir aquél que reniega de las formas y narrativas dominantes, comienza en la década del 60 con los cortometrajes producidos en el marco del Instituto Di Tella o los trabajos del Grupo de los Cinco, todo en el marco internacional del surgimiento de 'nuevas olas' o 'nuevos cines' (de Estados Unidos a Japón, pasando por Francia, Alemania, República Checa o Brasil).

Sin embargo, aquí es necesario realizar una distinción, siguiendo a Andrés Denegri (2012). Dentro de las expresiones vanguardistas habría que distinguir el cine clandestino, el cine experimental y el cine underground. El primero es un cine de contra-información, militante, contrario al modelo socio-económico-político-estético imperante, que busca agitar las conciencias y adoctrinar. El segundo es un cine realizado más bien en solitario, que enrarece la narración hasta el punto de que pueda plantearse su ausencia, concentrado exclusivamente en jugar con las capacidades de registro de la cámara y con la plasticidad del medio fílmico o digital. El cine underground, por su parte, mantiene las inquietudes políticas del clandestino, pero las desplaza hacia cuestiones relacionadas con la moral. Busca, de esta forma, evidenciar las represiones e hipocresías que sostienen a la sociedad. Para ello, reniega de la financiación estatal o de grandes productoras privadas y de las estéticas hegemónicas. Ya no busca adoctrinar o no espera ser herramienta del cambio revolucionario, pero sí intenta develar.

El ejemplo que me gustaría traer a colación aquí se enmarca en este último tipo de cine de vanguardia. Según David Oubiña (2004), el underground nacional se inicia con el estreno en 
1969 de The Players vs. Ángeles Caídos, largometraje de Alberto Fischerman, al que podríamos sumar el de Tiro de Gracia de Ricardo Becher ese mismo año. Pero con la llegada de la dictadura de 1976 estas expresiones quedarán truncas. Sin embargo, a principios de los ochenta, hay un cineasta que retoma la herencia under: Jorge Acha.

En Habeas Corpus (1986), su primer largometraje, rodado en 16 milímetros entre 1983 y 1984, nos cuenta el padecimiento de un detenido-desaparecido en su celda, en los momentos entre las sesiones de tortura, durante la Semana Santa. Intercaladas, escenas del accionar de su carcelero-torturador y de juegos en la playa con otro muchacho. Veamos cómo el montaje trabaja a nivel del interpretante, por desplazamiento de metáforas y repetición. Consideremos estas dos secuencias consecutivas. Ilustraré con fotogramas colocados en orden según aparecen en la película (omito algunos planos del montaje para sintetizar).

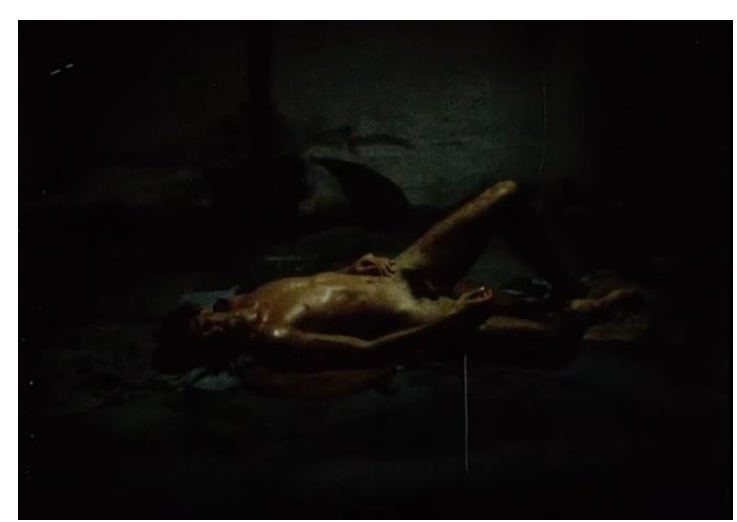

Figura 1. Acha, J. (1986).

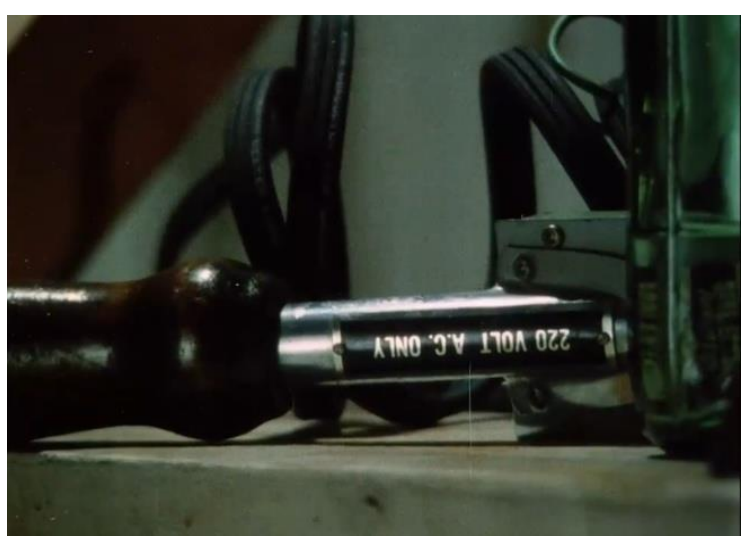

Figura 3. Acha, J. (1986).

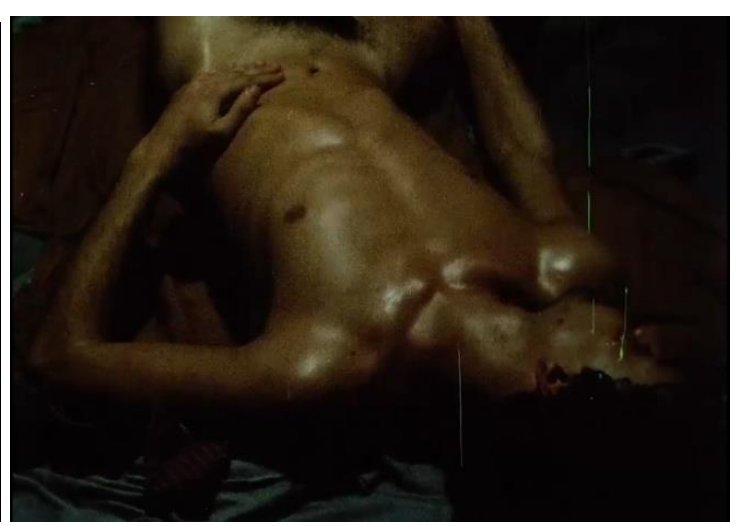

Figura 2. Acha, J. (1986).

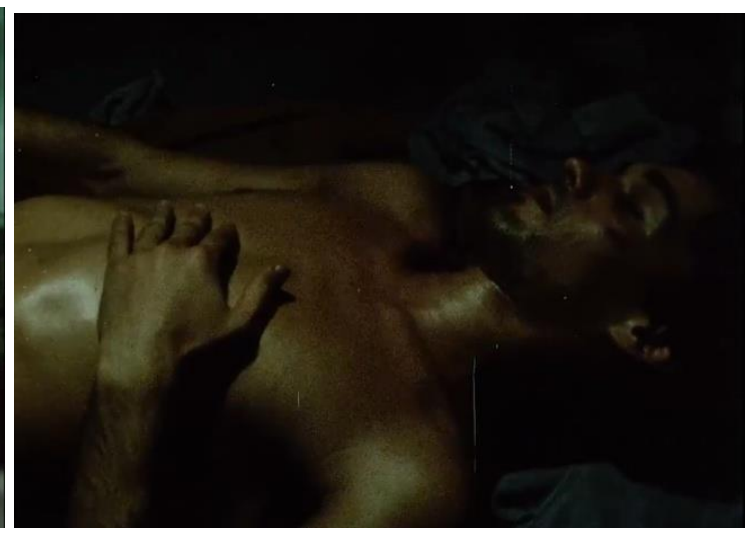

Figura 4. Acha, J. (1986). 


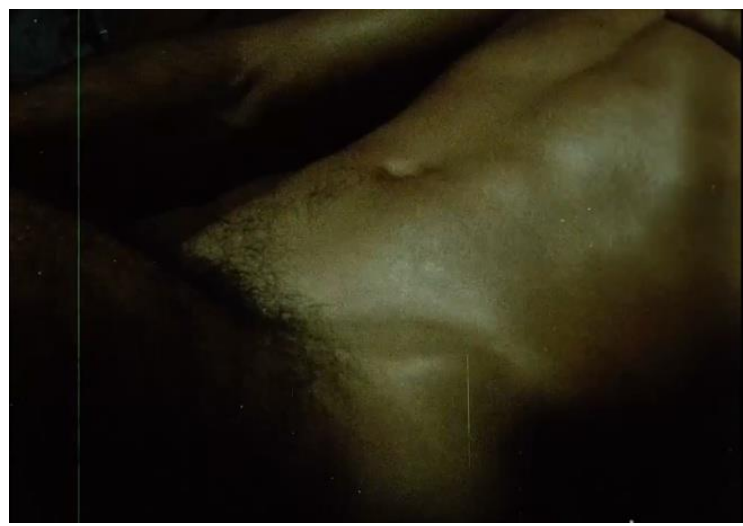

Figura 5. Acha, J. (1986).

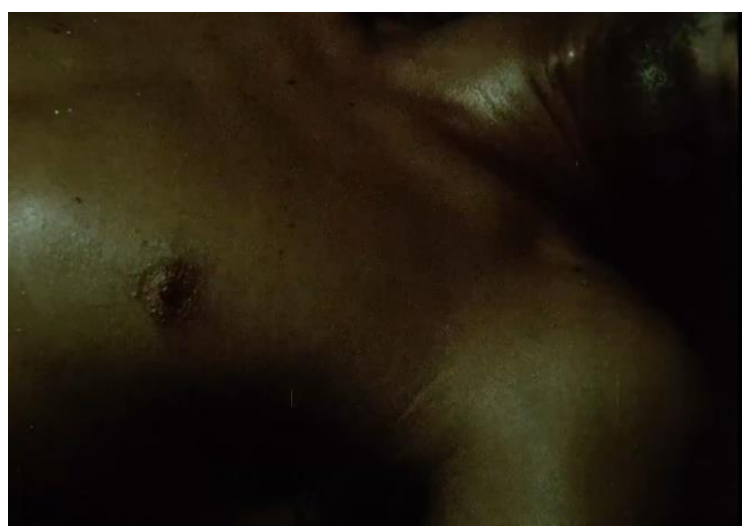

Figura 7. Acha, J. (1986).

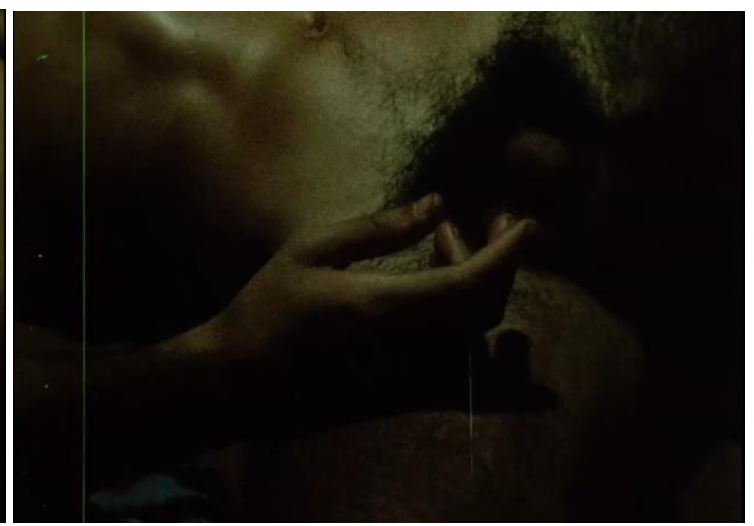

Figura 6. Acha, J. (1986).

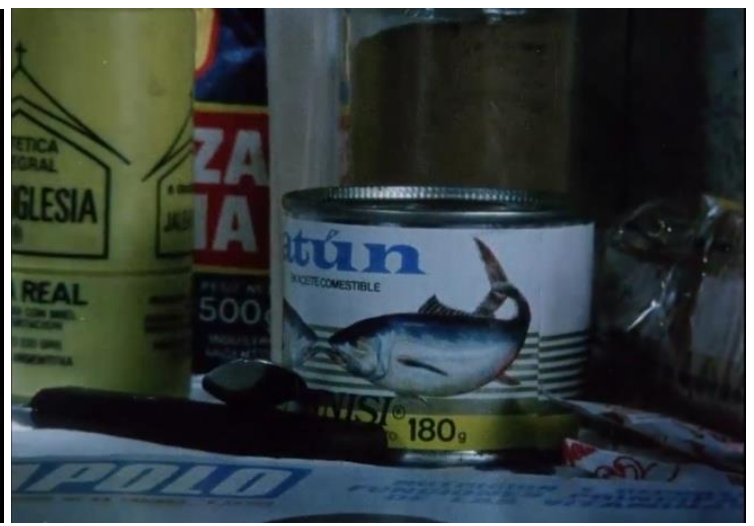

Figura 8. Acha, J. (1986).

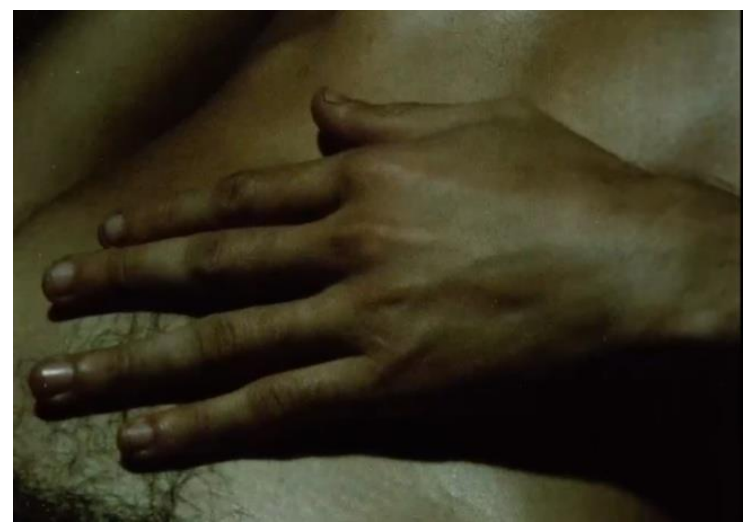

Figura 9. Acha, J. (1986).

El primer fotograma nos muestra el plano del detenido-desaparecido tirado desnudo en su celda. A partir del segundo, el plano se va cerrando, lo que fragmenta el cuerpo. Recordemos lo que decía Benjamin sobre la ruina y el cuerpo despedazado en el barroco. El tercer 
fotograma aquí incluido nos muestra una picana. Luego, continúa la fragmentación del cuerpo del hombre. En el cuarto y noveno fotogramas, vemos cómo busca reconocerse, percibirse, con su mano derecha: la acción de la picana ha contribuido a su noción consciente de ser un cuerpo, de estar situado. Cerca del final, se intercala el plano de una lata de atún. Por el contexto general del filme, podemos decir que ésta se halla en la cocina del centro clandestino, donde el torturador pasa sus ratos libres mientras ojea revistas de fisicoculturismo (contraste cuerpo hipertrofiado, idealizado del capitalismo - cuerpo triturado, real del capitalismo).

Pero es la narración que acompaña estas imágenes la que ofrece semióticamente una clave para su comprensión:

"Jesús es despojado de sus vestiduras. Caemos de rodillas ante la desnudez del desnudado. Ya no posee nada pero es la verdad desnuda (...) Ahora puedes repetir sus palabras eucarísticas: 'éste es mi cuerpo ofrecido por vosotros, nada lo cubre más. Se ha despojado de todo por ti. Se ha desnudado de sus vestiduras y se desnudará ahora también de su sangre (...)"'.

Ichtys: pez, en griego. También, un símbolo con la forma del perfil de un pez, empleado por los cristianos primitivos como seña secreta. El pez es Jesús. Jesús es el desaparecido (Bertazza, 2017). El desplazamiento metafórico estalla en la secuencia siguiente, donde la narración radial del sacerdote es sustituida por música lírica pop. Los peces (y la sangre) proliferan.

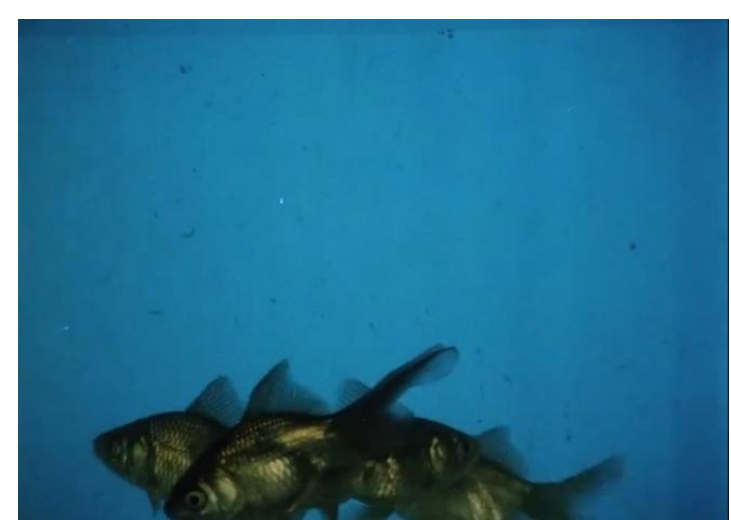

Figura 10. Acha, J. (1986).

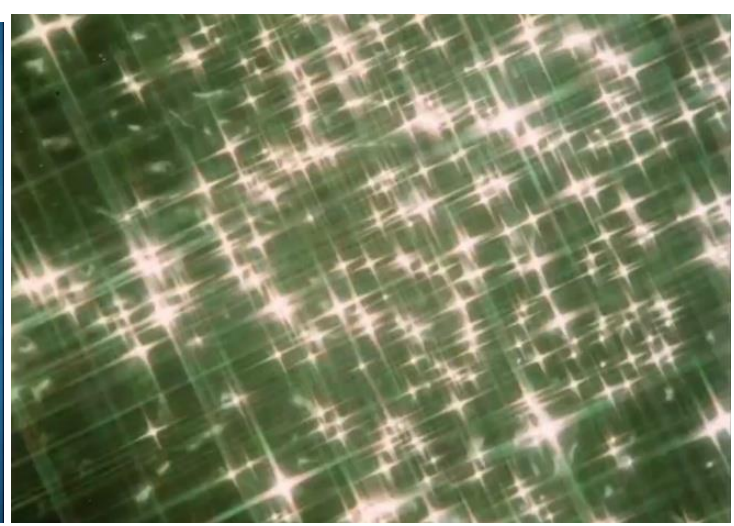

Figura 11. Acha, J. (1986). 


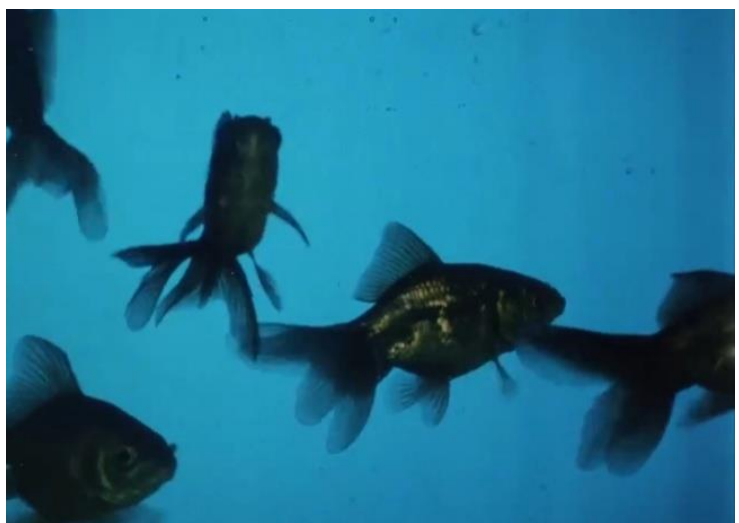

Figura 12. Acha, J. (1986).

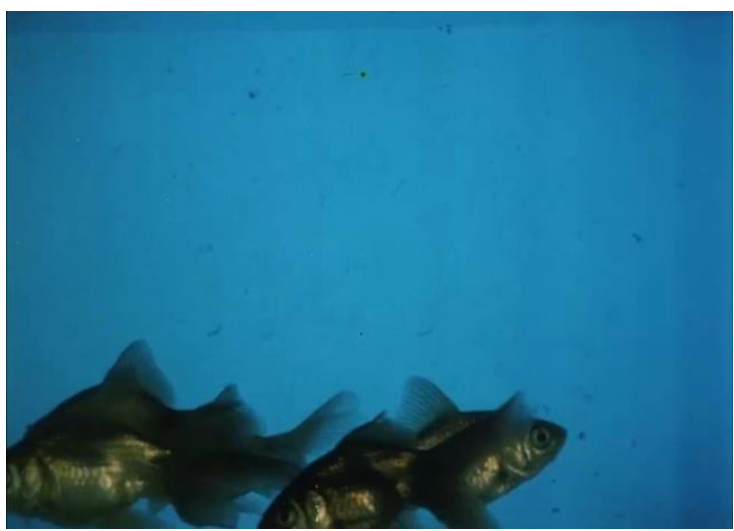

Figura 14. Acha, J. (1986).

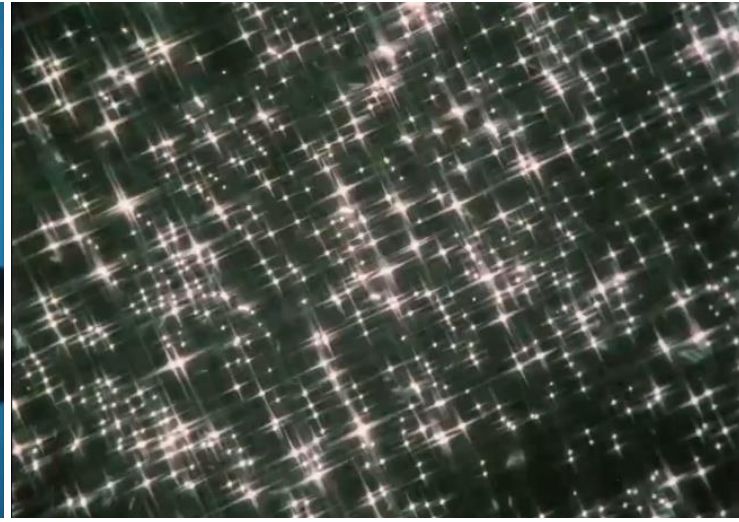

Figura 13. Acha, J. (1986).

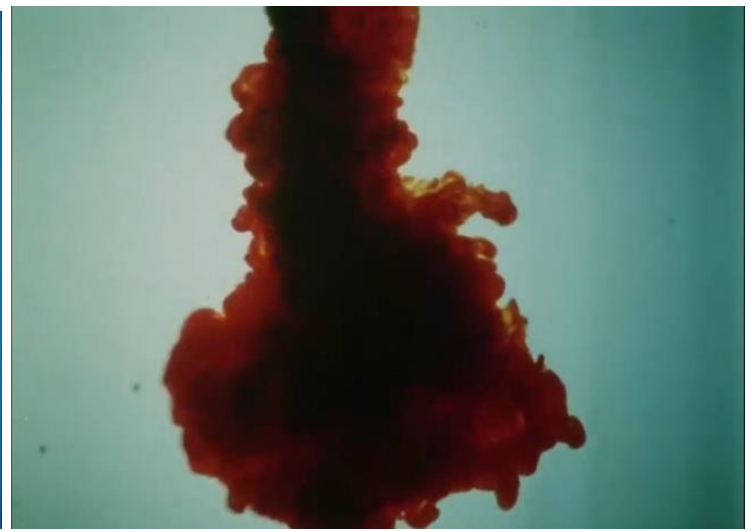

Figura 15. Acha, J. (1986).

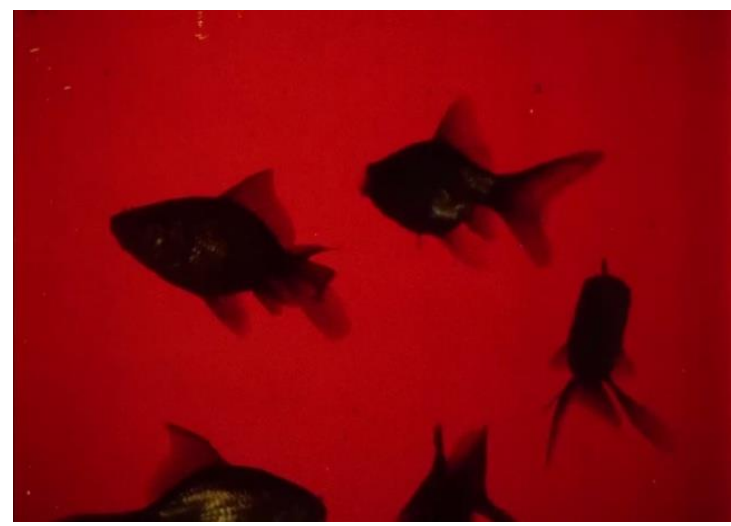

Figura 16. Acha, J. (1986).

Vale decir que los planos en los filmes de Acha son de muy breve duración, ya sea por una búsqueda estética específica o por las limitaciones propias del equipamiento a su disposición (una cámara Bollex a cuerda — habitual en el cine avant-garde del siglo XX-imposibilitada de 
tomar planos de más de treinta segundos). La combinación entre la breve pero distinta duración de los planos, los tipos de cortes (regular, encadenados, fundidos a negro) y el sonido fantasmático, de fuentes secundarias, o traído por el viento, consigue un ritmo particular, una respiración capaz de conformar estructuras alegóricas y metonímicas.

De esta forma, antes que un montaje dialéctico (ruso) que funcione por oposiciones (con el que, de todas formas, tiene mucho que ver), lo que tenemos es un montaje barroco que funciona en dos niveles: en primer lugar, por acumulación de metáforas sucesivas (relato radial sobre Cristo sobre imágenes del detenido encerrado intercaladas por la imagen de un pez enlatado y continuado por planos de peces en una pecera) y, en segundo lugar, por evocación a la distancia (lo visto en una secuencia se completa por lo que ocurre en una secuencia posterior, repetición de motivos visuales y sonoros).

La alegoría aparece en el reenvío de un signo a otro distinto de sí, aparece en el trabajo del interpretante. De este modo, se produce la 'escalada' que lleva del cuerpo del detenidodesaparecido al pez y, en consecuencia, al agua, y entonces a Cristo, sin que esta relacionalidad esté realmente explicitada, sino que exige del trabajo del espectador, de la puesta en juego de sus experiencias y conocimientos que harán variar, en cada experiencia particular, los interpretantes posibles que habrá de generar el montaje.

Como explica Adrian Ivakhiv:

\begin{abstract}
Un modelo procesual-relacional toma a la película no sólo como aquello que sale del estudio o aquello que es visible en la pantalla. Más bien, un film es lo que un film hace. Y lo que hace no es sólo lo que ocurre mientras uno lo mira. Es también lo que se revela cuando los espectadores reflexionan luego de verlo, y cuando la película reverbera a través del espacio entre el mundo del film y el mundo real, filtrándose en las conversaciones y en los sueños, tiñendo al mundo y haciéndolo vibrar de formas particulares, inyectando imágenespensamiento, sensaciones, motivaciones, receptividades incrementadas a esto o aquello, en los campos sociales y ecológicos más amplios dentro de los que los signos, significados y afectos de la película resuenan (2013: 12-13).
\end{abstract}

También, debemos agregar, no deben desentenderse las condiciones de producción (los sujetos involucrados, los recursos materiales, los escenarios, los procesos energéticos) que hacen al despliegue del continuum ideal-material realizado por la perspectiva peirceana.

En el ejemplo de Habeas Corpus vista desde la concepción peirceana del signo (y de la representación) vimos cómo se generaban interpretantes (la tercera pata del signo) tanto a nivel de la banda visual como sonora (por ejemplo, el reenvío entre las imágenes de peces, el 
cuerpo del detenido, las invocaciones a Cristo), pero también sugerimos un diálogo con las técnicas y tecnologías empleadas.

\section{Discusión}

La perspectiva aquí defendida, en consecuencia, posee dos niveles en mutua interrelación: en el plano sintagmático o inmanente, el trabajo del signo peirceano implica una determinada manera de comprender el encadenamiento de imágenes y sonidos, donde, a partir de un signoimagen $o$ de un signo-elemento del plano en particular, podemos notar las ramificaciones semióticas que genera en otros signos-imágenes $o$ en otros signos-elementos del plano sucesivos (o en resonancia entre planos y elementos distantes entre sí, separados en el encadenamiento por otros planos y elementos). Hablamos aquí de un despliegue.

En segundo lugar, en un plano paradigmático o transversal, la película (o cualquier obra de arte) implica a una serie de textos-otros que dialogan directa o indirectamente con ella, de procesos técnicos, de procesos material-energéticos, de relaciones humanas (laborales, afectivas, etcétera). Es quizás en este punto donde más evidente sea la perspectiva de la representación no mentalística (v. g. la del signo saussureano) sino semiótica.

Consideramos que Adrian Ivakhiv (2013), desde una posición ecocrítica que mucho tiene de comunicológica, ha sabido desarrollar el potencial antihilemórfico de la mirada aquí desarrollada en relación al análisis cinematográfico.

De este modo, a partir de Peirce, pero también de Guattari y sus tres ecologías, la cosmomorfia (creación de mundos) cinematográfica poseerá tres dimensiones existenciales:

1. La geomórfica u objetomórfica, que trata de la producción de territorialidad, de un aquí y un allí, de espacios públicos y privados. "Si los films producen mundos, esta productividad se ancla, en cierto grado, en una reproducción del mundo pre-cinematográfico o 'profílmico' existente. Pero el cine sólo reproduce fragmentos de ese mundo, rasgos o elementos desconectados de su milieu original y reconectados para formar uno nuevo, cinematográfico" (2013: 8).

2. La biomórfica o animamórfica: "con su 'ilusión' de movimiento entre objetos e imágenes, el cine nos muestra cosas que ven, sienten e interactúan y que, en consecuencia, aparecen animadas." Las películas "producen la textura sensual de lo que parece ser vida: una relacionalidad interperceptiva de cosas, que conforma un continuum de lo apenas vivo a lo reconociblemente social" (Ídem). Tiene que ver con "las diferentes formas en que el cine da forma a nuestro ver y sentir los mundos que produce y, asimismo, del mundo en que vivimos" 
(2013: 9). Es fácil notar la influencia de Whitehead en el énfasis relacional de esta dimensión, así como también en la importancia dada al continuo experiencial que implica la percepción desde lo inorgánico hasta lo orgánico. Esta relacionalidad, que es forzosamente productiva, funciona a nivel del interpretante.

3. La antropomórfica o sujetomórfica: "el cine nos muestra sujetos humanos o humanoides, seres que, entendemos, son arrojados a un mundo de circunstancias y posibilidades como nosotros". En este registro, "lo humano y lo reconociblemente social se distingue de lo no-, in-, sub- humano y del Otro distinto del humano; y lo 'cultural' o 'civilizado' se distingue de lo natural, salvaje, extranjero, bárbaro o monstruoso" (Ídem). Involucra las distinciones entre diferentes grupos humanos: las mujeres, los no-blancos, los indígenas suelen ser colocados en una relación más cercana con la naturaleza -en su sentido vulgar- que los hombres blancos europeos. En lo habitual, esto implica un rebajamiento o, en el mejor de los casos, una valoración etnocéntrica de la barbarie (o de lo femenino).

Por lo tanto, lo geomórfico refiere al mundo presentado como dado; lo antropomórfico, al mundo presentado como abierto a la acción, como agencia o capacidad de acción y creatividad. Son dos términos de un continuo

\begin{abstract}
entre los que se despliega un campo de posibilidades en el que la acción y la reacción, la percepción y la respuesta, tienen lugar. En este sentido, lo geomórfico, lo biomórfico y lo antropomórfico no son capas distintas del mundo. Más bien, lo geomórfico u objetomórfico y lo antropomórfico o sujetomórfico son dos términos de un continuum desplegado que está en sí mismo constituido de interperceptividad e interactividad. Es aquí, en el medio, que la acción de crear mundo tiene lugar; por esta razón, el término animamórfico es quizás más resonante que biomórfico, desde que sugiere una animicidad, una interactividad, el hasta y el hacia del encuentro abierto, que éste no implica necesariamente (Ivakhiv, 2013: 10).
\end{abstract}

Ivakhiv señala que estos tres morfismos generan un mundo que, entonces, se despliega de lo objetivo a lo subjetivo y viceversa. Vimos cómo la concepción del signo de raíz peirceana permite pensar realidad y procesos de significación en un mismo plano de inmanencia, recuperando la corporalidad perdida en concepciones del signo más bien mentales (o donde los frentes mental y material se encuentran separados ontológicamente), como las que lo dividen, y he aquí otra manifestación del dualismo, en significante y significado o los que pretenden escindir, al menos en parte, signo de símbolo.

Así llegamos a la idea de alegoría en Benjamin, alternativa a la concepción de símbolo de raíz cassirereana y ejemplificamos a partir de una obra del arte cinematográfico underground argentino. 
Se trata, en definitiva, no sólo de cómo la concepción triádica del signo de Peirce plantea una alternativa al dualismo forma/materia, sino también de cómo implica una comprensión del mundo y de la obra de arte no como sustancias o representaciones (psicológicas) sino como complejos de relaciones experienciales, como acontecimientos. Siguiendo a Adrian Ivakhiv podría decirse que estamos ante una mirada procesual-relacional. También podríamos caracterizarla de comunicacional. Distinguiríamos así tres niveles de la imagen en comunicación mutua indetenible: el contenido, la imagen y la idea, que remitirían al signo peirceano: objeto, signo (representamen) e interpretante (el todo abierto, nunca dado).

Todo esto supone, a su vez, una actualización de la concepción triádica de las cosas según Peirce: primeridad, segundidad y terceridad se transforman en el mundo que ofrece la obra de arte, la experiencia artística (cómo respondemos ante la obra) y lo que Ivakhiv llamaría el contexto de relaciones socio-ecológicas dentro del cual la obra es hecha, compartida, analizada y transformada por la experiencia.

\section{Bibliografía}

Acha, J. L. (1986). Habeas Corpus [largometraje]. Argentina.

Barad, K. (2007). Meeting the Universe Halfway: Quantum Physics and the Entanglement of Matter and Meaning. Durham y Londres: Duke University Press.

Benjamin, W. (2012). El origen del Trauerspiel alemán. Buenos Aires: Gorla.

Bertazza, J. P. (2017). El pez y los pecados en Habeas Corpus. En Bernstein, G. (ed.). Jorge Acha. Una eztétyka sudaka. Buenos Aires: Ítaca.

Cassirer, E. (2015). Antropología filosófica. EpubLibre. Recuperado de https://www.epubgratis.org/antropologia-filosofica-ernst-cassirer/

Denegri, A. (2012). Cine underground, cine clandestino, cine experimental: hacia una definición. Cibertronic, revista de artes mediáticas, 8. UNTREF, Tres de Febrero. Recuperado de http://www.untref.edu.ar/cibertronic/lo_trans/nota03/index.html

Dewey, J. (1929). Experience and Nature. Londres: George Allen \& Unwin, Ltd.

Ivakhiv, A. J. (2013). Ecologies of the moving image. Cinema, affect, nature. Waterloo: Wilfrid Laurier University Press.

Mullarkey, J. (2009). Refractions of reality. Philosophy and the Moving Image. Londres: Palgrave Macmillan.

Oubiña, D. (2004). Un cine subterráneo. Todavía, 7, OSDE, Buenos Aires. Recuperado de http://www.revistatodavia.com.ar/ 
Peirce, C. S. (2017). ¿Qué es un signo? En Obra filosófica reunida (Tomo II). EpubLibre.

Tabarrozzi, M. (2016). Crisis de consciencia. La aparición del pueblo en cuatro filmes del cine moderno argentino (1959-1988). (Tesis de Maestría). Estética y Teoría de las Artes, FBA, UNLP. Recuperado de http://hdl.handle.net/10915/58930

Visnovsky, E. (2018). On the interconnection between Peirce's pragmatism and semiotics. En Gvozdiak, V. y Svantner, M. (eds.). How to make our signs clear. C. S. Peirce and semiotics. Leiden, Boston: Brill Rodopi. 